\section{Analisis Kelayakan Desain Material Recovery Facility (Mrf) Dalam Pengelolaan Sampah Di Tpa Hutan Panjang Kota Banjarbaru}

\section{Candra Yuliana}

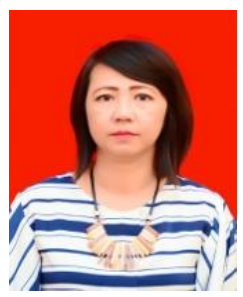

Penulis adalah staff pengajar Program Studi Program Profesi Insinyur Universitas Lambung Mangkurat. Bidang keahlian penulis adalah teknik struktur khususnya struktur beton bertulang, modelling komputer struktur bangunan, dan assesment keruntuhan bangunan. buletinppi@ulm.ac.id

\section{Pendahuluan}

Peningkatan jumlah penduduk yang terjadi dari tahun ke tahun membuat permasalahan tentang sampah ini menjadi semakin kompleks terkait karena pertambahan jumlah penduduk yang berbanding lurus dengan jumlah sampah yang dihasilkan. Kepadatan penduduk rata-rata Kota Banjarbaru sebesar 538 jiwa perkilometer persegi. Volume timbulan sampah Kota Banjarbaru rata-rata sebesar 526,516 m3/hari atau setara dengan 44,916 Ton/hari.

Kurangnya kesadaran masyarakat dalam upaya pengelolaan sampah yaitu pemilahan sampah, pengolahan dan pemanfaatan dari hulu (rumah tangga) ditambah lagi dengan kondisi dan situasi Kota Banjarbaru yang semakin padat penduduk dan sempit lahan, produksi sampah yang meningkat setiap hari dan gangguannya terhadap keseimbangan kualitas lingkungan hidup yang tidak dapat lagi ditolelir sementara sistem dan sarana penanganan dan pengolahan yang ada tidak mampu mengatasinya dengan cepat menyebabkan perlunya dilakukan pendirian unit pengolahan sampah di hilir (TPA) untuk mereduksi sampah sebelum dibuang ke landfill TPA. Salah satu alternatif unit pengolahan sampah yaitu dengan adanya Material Recovery Facility (MRF).
Pengelolaan sampah di Kota Banjarbaru masih belum maksimal. Hal ini terlihat dari sampah yang dikumpulkan di TPS kemudian diangkut dan ditimbun begitu saja di landfill TPA tanpa pengolahan. Perencanaan Material Recovery Facility (MRF) di TPA Hutan Panjang Gunung Kupang Kota Banjarbaru dapat digunakan sebagai salah satu alternatif untuk mengurangi volume sampah yang masuk ke TPA Hutan Panjang, menghemat kebutuhan lahan landfill, dan memperpanjang umur lahan TPA. Pengelolaan yang dilakukan adalah komposting sampah organik dengan sistem open windrow dan pemanfaatan kembali sampah anorganik yang mempunyai nilai jual. Komponen MRF yang dibutuhkan adalah lahan pemilahan, lahan penempungan sampah organik, lahan pencampuran sampah organik dengan EM4 (biostater), lahan pengomposan, tempat penyimpanan sampah kering (barang sortir), tempat penyimpanan kompos serta kantor administrasi. Lahan yang dibutuhkan untuk bangunan pengolahan sampah (MRF) adalah 12031,5 $\mathrm{m} 2$ dan rencana anggaran biaya yang diperlukan untuk biaya pembangunan dan penyediaan peralatan MRF sebesar Rp 10.563.047.380,00. Berdasarkan analisis kelayakan ekonomi dengan berbagai alternatif pembiayaan baik itu dengan pembiayaan dari pemerintah ataupun dengan pinjaman lunak menunjukkan pembangunan MRF ini layak untuk direalisasikan.

Kata kunci: Analisa Ekonomi, Banjarbaru, Komposting, Material Recovery Facility

www.buletinppi.ulm.ac.id

Material Recovery Facility (MRF) adalah fasilitas daur ulang yang menggabungkan beberapa teknik pengolahan sampah semaksimal mungkin dengan residu yang seminimal mungkin seperti pemilahan sampah, 3R (reduce, reuse, dan recycling), dan komposting. Desain MRF dapat memberikan keuntungan dalam penanganan pengolahan sampah relatif lebih cepat, tepat guna dan ramah lingkungan, menghemat kebutuhan lahan landfill, memperpanjang umur lahan TPA.

Sampah adalah bahan buangan padat yang dibuang, tidak terpakai dan/atau tidak disenangi yang umumnya berasal dari kegiatan manusia (Tchobanoglous, 1993). Dalam kamus istilah lingkungan (1996), sampah diartikan suatu bahan yang terbuang atau dibuang dari sumber hasil aktivitas manusia maupun proses alam yang belum memiliki nilai ekonomis.

Berdasarkan sumber-sumber sampah (Rahman, 2004) menguraikan bahwa sampah dapat berasal dari:

a. Permukiman

Umumnya sampah rumah tangga berupa sisa dari pengolahan makanan, perlengkapan rumah tangga bekas, kertas, kardus, gelas, kain, sampah kebun/halaman dan lain-lain. 
b. Pertanian dan perkebunan

Sampah dari kegiatan pertanian tergolong bahan organik seperti jerami, dan sejenisnya. Sampah bahan kimia seperti pestisida dan pupuk buatan perlu perlakuan khusus agar tidak mencemari lingkungan. Sampah pertanian lainnya adalah lembaran plastik penutup tempat-tempat tumbuh-tumbuhan yang berfungsi untuk mengurangi penguapan dan penghambatan pertumbuhan gulma, namun plastik ini bisa di daur ulang.

c. Sisa bangunan dan kontuksi gedung Sampah yang berasal dari kegiatan pembangunan dan pemugaran gedung, ini bisa berupa bahan organik maupun anorganik. Sampah organik, misalnya: kayu, bambu, triplek. Sampah anorganik, misalnya: semen, pasir, spesi, batu bata, ubin, besi dan baja, kaca dan kaleng.

d. Perdagangan dan perkantoran

Sampah yang berasal dari daerah perdagangan seperti; toko, pasar tradisional, warung, pasar swalayan ini terdiri dari kardus, pembungkus, kertas, dan bahan organik, termasuk di dalamnya sampah makanan dan restoran. Sampah yang berasal dari lembaga pendidikan, kantor pemerintah dan swasta biasanya terdiri dari kertas, alat tulis-menulis, toner foto copy, pita printer, kotak tinta printer, baterai, bahan kimia dari laboraturium, pita mesin ketik, klise film, komputer rusak, dan lain-lain.

e. Industri

Sampah ini berasal dari seluruh rangkaian proses produksi (bahan-bahan kimia serpihan/potongan bahan), perlakuan dan pengemasan produk (kertas, kayu, plastik, kain/lap, yang jenuh dengan pelarut untuk pembersihan). Sampah industri berupa bahan kimia yang seringkali beracun juga memerlukan perlakuan khusus sebelum dibuang.

Material yang biasanya dipilah untuk recyling (Tchobanoglous, Theisen, Vigil, 1993) adalah aluminium, kertas, plastik, kaca, logam besi dan non besi, pembersihan jalan, bongkaran bangunan. Plastik dapat menjadi sangat sulit didaur ulang karena beberapa barang plastik terbuat dari berbagai macam jenis plastik yang berbeda. Jenis-jenis plastik tersebut harus dipisah-pisahkan sebelum didaur ulang. Berikut ini akan diuraikan jenis-jenis plastik (Margareta, 2011):

1) PETE atau PET

PET adalah singkatan dari Polyethylene Terephthalate yang dikenali dengan kode 1 pada kemasan plastik. PET meruakan plastik yang umum digunakan diseluruh dunia dan dapat pada botol air, botol soda, botol jus, botol minyak goreng, kemasan makanan, dan lain-lain. PET memiliki ciri-ciri jernih, kadang berwarna hijau, tahan lama, kuat, ringan, dan mudah dibentuk ketika panas.
2) HDPE

HDPE adalah singkatan dari High Density Polyethylene yang dikenali dengan kode 2 pada kemasan plastik. HDPE biasanya berwarna pekat, tidak tembus pandang, dan dapat muncul dengan berbagai warna, tetapi bisa juga setengah transparan. HDPE dapat ditemukan pada botol detergen, botol obat, botol kosmetik, galon air minum, tupperware, kresek, tutup botol dan lainlain.

3) PVC

PVC adalah singkatan dari Polyvinyl Chloride yang dikenali dengan kode 3 pada kemasan plastik. PVC berciri-ciri tipis, transparan, ringan, halus, dan tidak tahan lama. PVC dapat dijumpai pada kabel listrik, mainan, pipa air, kemasan makan cepat saji, kotak makan sekali pakai, dan lain-lain.

4) LDPE

LDPE adalah singkatan dari Low Density Polyethylene dan dikenali dengan kode 4 pada kemasan plastik. LDPE memiliki ciri-ciri bisa tembus cahaya ataupun pekat, sangat kuat, lentur, kedap air dan dapat dijumpai pada kantong plastik lentur, kota penyimpanan, mainan, perangkat komputer, dan lain-lain.

5) $\mathrm{PP}$

PP adalah singkatan dari Polypropylene dan dikenali dengan kode 5 pada kemasan plastik. PP memiliki ciri-ciri dapat tembus cahaya ataupun pekat, lentur, kuat dan kedap air. PP dapat dijumpai pada gelas minuman, cup plastik, sedotan, dan beberapa macam botol.

6) PS

PS adalah singkatan dari Polystyrene dan dikenali dengan kode 6. PS memiliki ciri-ciri dapat tembus cahaya, fleksibel pada batas tertentu namun secara umum kaku. PS dapat ditemui pada styrofoam, peralatan makan sekali pakai seperti sendok, garpu dan lain-lain.

7) OTHER

OTHER merupakan jenis plastik campuran dengan kode nomer 7. Produk plastik dengan kode nomer 7 terbuat dari campuran beberapa jenis plastik dengan kode 1 hingga 2.

\section{Material Recovery Facility (MRF)}

MRF merupakan suatu fasilitas pengelolaan sampah yang memiliki sistem pemilahan sampah dan recycling (Hapsari, 2006). Komponen-komponen sampah yang dapat dipisahkan, terdiri sampah basah dan kering. Sampah kering yang dapat dikelola antara lain adalah kertas, plastik, kaca dan logam, sedangkan sampah basah dapat dimanfaatkan sebagai kompos. Pada dasarnya tujuan dari penerapan MRF sebagai sistem pengelolaan sampah terpadu adalah untuk mereduksi volume sampah yang akan masuk ke tempat pembuangan akhir. Kegiatan pokok yang dilakukan di lokasi Material Recovery Facility meliputi 
(Al Mudhar, 2002) pemilahan sampah, pengelolaan lanjut sampah, pengolahan sampah, dan peningkatan mutu produk daur ulang.

Desain MRF terdiri dari tiga tahapan (Tchobanoglous, et.al., 1993), yaitu analisis kelayakan (rencana pengelolaan sampah, desain konsep, pertimbangan ekonomi, sistem pemilikan dan pengoperasian, sistem usaha), perancangan awal, dan perancangan akhir.

\section{Metode}

Tahapan perencanaan MRF di TPA Hutan Panjang Kota Banjarbaru meliputi:

a. Tahap Persiapan

Tahap persiapan dalam perencanaan ini meliputi berbagai kegiatan awal yang menunjang rumusan permasalahan, tujuan, studi literatur, serta peralatan yang diperlukan dalam pengambilan data primer.

b. Tahap Survey dan Pengumpulan Data

Survey yang dilakukan langsung ke lapangan untuk mendapatkan data primer yang meliputi timbulan sampah dan komposisi sampah dengan cara sampling yang sesuai dengan SNI 19-3964-1994, karakteristik (kadar air dan kadar volatil sampah), harga barang lapak. Survey juga dilakukan ke instansi terkait untuk memperoleh data-data sekunder.

c. Tahap Pengolahan Data

Tahap selanjutnya adalah mengolah data yang telah diperoleh baik itu data primer maupun sekunder dengan proyeksi hingga 20 tahun ke depan (2012 - 2032).

d. Tahap Perencanaan

Tahap ini merupakan tahap akhir dari kegiatan ini yaitu perencanaan MRF di TPA Hutan Panjang Kota Banjarbaru yang menghasilkan laporan berisi metode pemilahan dan daur ulang, diagram alir material, loading rate, recovery factor, mass balance, kebutuhan SDM, penampung lindi kompos, kebutuhan lahan dan layout MRF, dan analisa kelayakan ekonomi MRF.

\section{Hasil dan Pembahasan}

\section{a. Umum}

Perencanaan MRF ini berlokasi di TPA Hutan Panjang Kawasan Gunung Kupang, Kelurahan Cempaka Kecamatan Cempaka Kota Banjarbaru. Pada tahun 2006 TPA Hutan Panjang memiliki luas lahan sebesar $10 \mathrm{Ha}$ dan pada tahun 2008 mengalami perluasan lahan sebesar 31,225 $\mathrm{Ha}$ (terdapat di sebelah utara lahan lama). Lokasi TPA Hutan Panjang dapat dilihat pada Gambar 1 dengan batas-batas administratif sebagai berikut:
- Sebelah Utara :Kecamatan Banjarbaru
Selatan
- Sebelah Selatan
:Kabupaten Banjar
- Sebelah Timur
:Kabupaten Tanah Laut

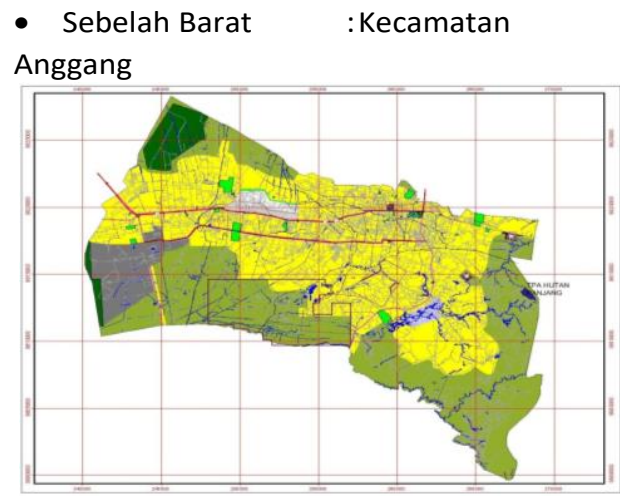

Gambar 1. Lokasi TPA Hutan Panjang

\section{b. Analisis Data dan Perencanaan}

\section{Timbulan dan Komposisi Sampah}

Dari hasil sampling didapat timbulan sampah rata-rata Kota Banjarbaru adalah 2,11 Liter/orang.hari atau 0,18 Kg/orang.hari. Komposisi sampah yang terdapat di Kota Banjarbaru berdasarkan komponen sampah basah sebesar 55,21\%, sampah kertas 9,09\%, kayu 5,36\%, kain 2,55\%, karet 2,70\%, plastik 10,97\%, logam-besi 3,78\%, kaca/botol $1,17 \%$ dan lain-lain $9,16 \%$. Komponen sampah rata-rata ditunjukkan pada Gambar 2.

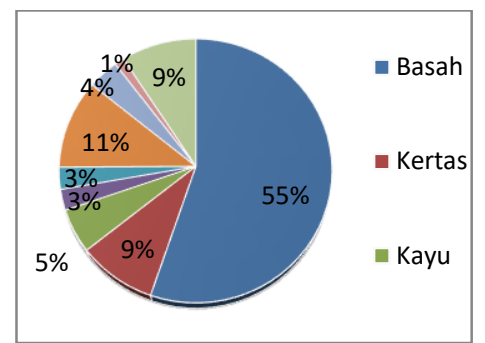

Gambar 2. Komposisi Sampah

\section{Mass Balance Sampah}

Perhitungan mass balance bertujuan untuk mengetahui jumlah sampah yang masuk, jumlah sampah yang dikelola di MRF dan jumlah sampah yang menjadi residu. Perhitungan ini juga menunjukkan seberapa efektif MRF yang direncanakan dalam mengurangi jumlah timbulan sampah.

Jumlah timbulan sampah pada tahun perencanaan yang masuk ke MRF mencapai 635,555 ton/hari. Pengelolaan sampah yang terjadi di MRF adalah menjual kembali sampah kering (barang lapak) layak jual dan melakukan komposting untuk sampah basah. Melalui penentuan recovery factor dan perhitungan mass balance jumlah sampah basah yang diolah menjadi kompos sebesar 294,001 ton/hari dan sampah kering (barang lapak) yang layak dijual jumlahnya sebesar 100,857 ton/hari melalui proses pemilahan, pengemasan dan penyimpanan pada MRF. Untuk lebih jelasnya dapat dilihat pada Tabel 1.

Tabel 1. Hasil Mass Balance Sampah Tahun Perencanaan (2032) 


\begin{tabular}{|l|c|c|c|c|}
\hline Komposisi & $\begin{array}{c}\text { Berat } \\
\text { sampah } \\
\text { (ton) }\end{array}$ & $\begin{array}{c}\text { Reduksi } \\
\text { sampah } \\
\text { (Pemulung) } \\
\text { (ton) }\end{array}$ & $\begin{array}{c}\text { Berat } \\
\text { recovery } \\
\text { Sampah di } \\
\text { TPA } \\
\text { (ton) }\end{array}$ & $\begin{array}{c}\text { Volume } \\
\text { Residu } \\
\text { (ton) }\end{array}$ \\
\hline $\begin{array}{l}\text { Sampah } \\
\text { dikomposkan }\end{array}$ & 350,878 & 0 & 294,001 & 56,877 \\
\hline $\begin{array}{l}\text { Sampah } \\
\text { dimanfaatkan } \\
\text { kembali }\end{array}$ & 284,677 & 25,715 & 100,857 & 158,105 \\
\hline Jumlah & 635,555 & 25,715 & 394,858 & 214,983 \\
\hline
\end{tabular}

\section{Lahan yang Dibutuhkan untuk MRF}

Sampah kering (barang lapak) yang telah dilakukan pemilahan berdasarkan komposisi di lahan pemilahan sampah akan dilakukan pengemasan kemudian disimpan di tempat penyimpanan sampah kering. Tempat penyimpanan sampah kering dihitung berdasarkan jumlah sampah kering yang telah dipilah. Sampah basah yang akan dikompos dilakukan pencacahan terlebih dahulu. Total lahan yang dibutuhkan dalam perencanaan MRF ini yaitu 12031,5 $\mathrm{m} 2$. Luas lahan yang dibutuhkan selengkapnya dapat dilihat pada Tabel 2.

\section{Pekerja yang dibutuhkan dalam Perencanaan MRF}

Pekerja dalam operasional MRF terdiri dari pekerja pemilah, pekerja pengemasan barang, pekerja pencacah sampah dan pengomposan, manajer operasional, manajer teknik, administrasi, operator dan pengawas penimbangan, operator mesin ayakan, dan petugas keamanan. Diperlukan tenaga pemilah sebanyak 73 orang masing-masing 18 orang untuk pemilahan sampah basah (organik), 2 orang untuk sampah ukuran besar dan kayu, 3 orang untuk pemilahan kertas, 4 orang untuk pemilahan kaca/botol, 11 orang untuk pemilahan logam-besi, 30 orang untuk pemilahan jenis-jenis plastik, 2 orang untuk sampah kain dan karet serta 3 orang untuk pemilahan sampah lain-lain dan residu. Penentuan jumlah pekerja pemilah berdasarkan kriteria sampah terpilah tiap pekerja menurut Tchobanoglous, et.al, (1993). Rincian kebutuhan pekerja selengkapanya dapat dilihat pada Tabel 3

Tabel 2. Kebutuhan Lahan MRF

\begin{tabular}{|l|c|}
\hline \multicolumn{1}{|c|}{ Komponen } & Luas Lahan (m2) \\
\hline Area penerima sampah & 1089 \\
\hline Tempat pemilahan sampah & 396 \\
\hline $\begin{array}{l}\text { Tempat penyimpanan sampah } \\
\text { kering }\end{array}$ & 7125 \\
\hline $\begin{array}{l}\text { Tempat penampungan sampah } \\
\text { basah dan alat pencacah }\end{array}$ & 676 \\
\hline $\begin{array}{l}\text { Lahan Pencampuran EM4 } \\
\text { (biostater) dengan Sampah } \\
\text { Organik }\end{array}$ & 6350 \\
\hline Lahan pengomposan & 682 \\
\hline $\begin{array}{l}\text { Lahan pengayakan dan } \\
\text { pengemasan }\end{array}$ & 576 \\
\hline Gudang penyimpanan kompos & \\
\hline
\end{tabular}

\begin{tabular}{|l|c|}
\hline Bak penampung lindi kompos & 256 \\
\hline Kantor & 35 \\
\hline Ruang pegawai & 36 \\
\hline Mushola & 20,5 \\
\hline Area parkir kendaraan & 27 \\
\hline Gudang peralatan & 20 \\
\hline Kantin & 20 \\
\hline Toilet Jumlah & 16 \\
\hline & 12031,5 \\
\hline
\end{tabular}

Tabel 3. Kebutuhan Tenaga Kerja MRF

\begin{tabular}{|c|l|c|}
\hline No & \multicolumn{1}{|c|}{ Tenaga kerja } & Jumlah \\
\hline 1. & Tenaga pemilah & 73 \\
\hline 2. & Tenaga pengemasan & 90 \\
\hline 3. & $\begin{array}{l}\text { Tenaga pencacah dan } \\
\text { pengomposan }\end{array}$ & 17 \\
\hline 4. & Manajer operasional & 1 \\
\hline 5. & Manajer teknik & 1 \\
\hline 6. & Administrasi & 3 \\
\hline 7. & $\begin{array}{l}\text { Operator dan pengawas } \\
\text { penimbangan }\end{array}$ & 3 \\
\hline 8. & Operator Mesin Ayakan & 11 \\
\hline 9. & Keamanan & 1 \\
\hline \multicolumn{2}{|c|}{ Jumlah } & 200 \\
\hline
\end{tabular}

\section{Analisis Ekonomi}

Keuntungan dan kerugian yang terjadi dalam operasional MRF dengan melakukan analisis ekonomi yang terjadi dari perhitungan modal tetap, biaya operasional MRF, perhitungan pendapatan dan analisis kelayakan ekonomi.

Kebutuhan modal tetap terdiri atas modal pembangunan dan modal peralatan tetap. Pembangunan MRF direncanakan dilakukan di TPA Hutan Panjang dengan kepemilikan lahan adalah Pemerintah Kota Banjarbaru. Perhitungan pada analisis kebutuhan modal pembangunan MRF mengacu pada Harga Satuan Pokok Kegiatan (HSPK) Kota Banjarbaru 2012. Modal pembangunan dan peralatan tetap yang dibutuhkan yaitu sebesar Rp 10.563.047.380,00.

Biaya operasional terdiri dari biaya pembelian peralatan operasional tahunan, biaya gaji pekerja, biaya pembelian bahan bakar untuk mesin pencacah dan pengayak, biaya rekening air dan listrik, biaya kemasan, dan biaya perawatan. Total biaya operasional MRF per tahun adalah sebesar Rp 6.488.773.306,00. Biaya pengeluaran operasional setiap tahun diperkirakan naik sebesar $10 \%$ (hasil survey).

Pendapatan MRF berasal dari penjualan sampah kering (barang lapak) layak jual dan produk kompos. Pendapatan dari penjualan sampah kering (barang lapak) dan kompos mencapai $\mathrm{Rp}$ 6.233.375.986,00/tahun. Produk kompos dijual dengan pembagian kemasan kompos halus dan kompos kasar masing-masing $5 \mathrm{~kg}, 25 \mathrm{~kg}$ dan $50 \mathrm{~kg}$. 
Untuk mengetahui layak tidaknya dibangun MRF maka dilakukan analisis kelayakan ekonomi menggunakan Net Present Value (NPV), Benefit Cost Ratio (BC Rasio), Internal Rate Of Return (IRR) dan Payback Period (PP). Berdasarkan perhitungan labarugi tiap tahun dalam periode 20 tahun dengan pembiayaan untuk modal tetap pembangunan MRF berasal dari $100 \%$ dana internal pemerintah menunjukkan bahwa operasional MRF memberikan keuntungan. Perhitungan NPV pada $\mathrm{i}=12 \%$ menghasilkan angka NPV adalah Rp 25.711.481.251,00; BC Rasio sebesar 1,236; IRR sebesar $22 \%$ serta periode pengembalian investasi (payback period) terjadi pada tahun ke-7 bulan ke-2 setelah proyek investasi berjalan. Adapun berbagai alternatif investasi (pembiayaan) yang dapat dilakukan apabila ketersediaan modal investasi dalam pembangunan MRF terbatas maka bisa melakukan pinjaman pada organisasi lain (pihak swasta) untuk membiayai pembangunan MRF yang tentunya akan ada suatu kesepakatan tentang jadual pengembalian baik induk maupun bunga dari pinjaman tersebut. Hasil perhitungan analisa kelayakan dengan suku bunga pinjaman lunak sebesar $10 \%$ dan jangka pengembalian peminjaman selama 10 tahun selengkapnya dapat dilihat pada Tabel 4 (lampiran).

Berdasarkan Tabel 4 menunjukkan bahwa nilai NPV > 0, BC Rasio > 1, IRR > MARR (suku bunga pinjaman yang berlaku), dan payback period (PP) $<$ dari umur suatu investasi, hal ini berarti MRF di TPA Hutan Panjang Kota Banjarbaru layak untuk direalisasikan.

\section{Kesimpulan}

Kesimpulan yang dapat diambil dalam perencanaan ini adalah:

a. Volume timbulan sampah Kota Banjarbaru ratarata sebesar 526,516 m3/hari atau setara dengan 44,916 Ton/hari dengan komposisi sampah basah sebesar $55,21 \%$, sampah kertas $9,09 \%$, kayu 5,36\%, kain 2,55\%, karet 2,70\%, plastik 10,97\%, logam-besi $3,78 \%, \mathrm{kaca} /$ botol $1,17 \%$ dan lain-lain 9,16\%.

b. Lahan yang dibutuhkan untuk bangunan pengolahan sampah (MRF) adalah 1,2 ha dan rencana anggaran biaya yang diperlukan untuk biaya bangunan dan peralatan MRF sebesar Rp 10.563.047.380,00.

c. Berdasarkan analisis kelayakan ekonomi dengan berbagai alternatif pembiayaan baik itu dengan pembiayaan dari pemerintah ataupun dengan pinjaman lunak menunjukkan pembangunan MRF ini layak untuk direalisasikan. Semakin besar pinjaman lunak untuk pembiayaan MRF maka semakin kecil nilai NVP, BC Rasio, IRR, semakin besar nilai payback period dan sebaliknya semakin kecil pinjaman lunak maka semakin besar nilai NVP, BC Rasio, IRR, semakin kecil nilai payback period.

\section{Saran}

- Dibutuhkan penelitian lanjutan mengenai recovery factor sampah basah agar lebih akurat karena sampah basah sangat dipengaruhi oleh musim. Selain itu juga dibutuhkan penelitian mengenai komposisi sampah plastik karena jenis sampah plastik yang ada sangat beragam. Hal tersebut nantinya akan berpengaruh terhadap pendapatan hasil penjualan kompos dan barang lapak.

- Dibutuhkan penelitian lanjutan mengenai kajian pemberdayaan masyarakat dalam mereduksi sampah dari sumber berdasarkan UU Nomor 18 Tahun 2008 agar perhitungan mass balance sampah dapat lebih akurat.

\section{Daftar Pustaka}

Al Mudhar, M. Hartono, R. Suryantoro, A. Hadi, A. 2002. Studi Penanganan Sampah Di Wilayah Surabaya Metropolitan. Laporan Hasil Penelitian. Kerjasama Badan Penelitian dan Pengembangan Jawa Timur dan Universitas Negri Malang.

Anwar, Chairil. 2012. Pengertian Sampah. http://www.ilmusipil.com/pengertian-sampah.

Diakses tanggal 17 Maret 2012.

BPS (Biro Pusat Statistik). Kota Banjarbaru Dalam Angka 2011. Kota Banjarbaru.

SNI 19-3964-1995 tentang Metode Pengambilan dan Pengukuran Timbulan dan Komposisi Sampah Perkotaan. 1995. Jakarta.

SNI 19-3983-1995 tentang Spesifikasi Timbulan Sampah untuk Kota Kecil dan Kota Sedang di Indonesia. 1995. Jakarta.

SNI 19-2454-2002 tentang Tata Cara Teknik Operasional Pengelolaan Sampah Perkotaan. 2002. Jakarta.

Dewi, T.Q. 2008. Penanganan dan Pengolahan Sampah. Penebar Swadaya. Jakarta.

Hadiwiyoto, S. 1983. Penanganan dan Pemanfaatan Sampah. Yayasan Idayu. Jakarta.

Hapsari, I. 2006. Pengembangan TPS sebagai Material Recovery Facility (MRF) di Kelurahan Tegalsari. Tugas Akhir. Jurusan Teknik Lingkungan. ITS. Surabaya.

Indah A, Dwi. 2011. Pengomposan. http://id.shvoong.com/writing-and-speaking.

Diakses tanggal 17 Maret 2012.

Kastaman, Roni., Kramadibrata, Ade Moetangad. 2007. Sistem Pengelolaan Reaktor Sampah Terpadu (SILARSATU). Humaniora. Bandung.

Margareta, Ananda Maya. 2011. Perencanaan Material Recovery Facility (MRF) Untuk Kawasan Wisata Kebun Binatang Surabaya (KBS) dan Permukiman Penduduk Kecamatan Wonokromo Di Kota Surabaya. Jurusan Teknik Lingkungan Fakultas Teknik Sipil dan Perencanaan Insititut Teknologi Sepuluh November Surabaya. 
Noviatun, L. 2007. Perencanaan Material Recovery Facility (MRF) Di TPA Lamongan. Tugas Akhir. Jurusan Teknik Lingkungan ITS. Surabaya.

Purwendro, Setyo. 2009. Mengolah Sampah Untuk Pupuk Dan Pestisida Organik. Penebar Swadaya. Depok.

Rahman, Haikal. 2004. Analisis Nilai Ekonomi Pengelolaan Persampahan Studi Kasus Dinas Kebersihan Kota Medan. Medan.

Shah, K. 2000. Basic of Solid and Hazardous Waste Management Tecnology. Prentice Hall PTR. Upper Saddle River. New Jersey.

Sudarso. 1985. Pembuangan Sampah. Pusat Pendidikan Tenaga Kesehatan Departemen Kesehatan. Surabaya.

Tchobanoglous, G. Theisen, H. \& Vigil, S.A. 1993. Integrated Solid Waste Management Engineering Principles and Management Issues. Mc Graw-Hill. Singapore.

Wikipedia. 2012. Nett Present Value (NPV). http://en.wikipedia.org/wiki/Net_present_value. Diakses tanggal 18 Maret 2012

Yuliana, Candra. 2008. Bahan Ajar Rekayasa Ekonomi. Universitas Lambung Mangkurat Press. Banjarmasin.

Yulio, Yandi. 2011. Pengelolaan Sampah. http://yandiyulio.wordpress.com. Diakses tanggal 18 Maret 2012. 